\title{
ETNOBOTÁNICA Y MEMORIA BIOCULTURAL EN SAN MARCOS TULIJÁ, CHILÓN, CHIAPAS, MÉXICO
}

\section{ETHNOBOTANY AND BIOCULTURAL MEMORY IN SAN MARCOS TULIJA, CHILON, CHIAPAS, MEXICO}

\author{
1*Miguel Angel PÉREZ- PÉREZ., ${ }^{2}$ Gabriela VERA- CORTÉS., ${ }^{3}$ Agustina Rosa ANDRÉS- HERNÁNDEZ., ${ }^{4}$ Rodolfo \\ MONDRAGÓN -RÍOS
}

\begin{abstract}
${ }^{1}$ El Colegio de la Frontera Sur. Departamento Agricultura, Sociedad y Ambiente. Unidad Villahermosa, Tabasco. *maperez@ecosur.edu.mx; ${ }^{2}$ El Colegio de la Frontera Sur. Grupo Académico Procesos Culturales y Construcción Social de Alternativas. Unidad Villahermosa, Tabasco. ${ }^{3}$ Benemérita Universidad Autónoma de Puebla. Facultad de Ciencias Biológicas. Puebla, Pue. ${ }^{4}$ El Colegio de la Frontera Sur. Grupo Académico Procesos Culturales y Construcción Social de Alternativas. Unidad San Cristóbal de Las Casas. Chiapas.
\end{abstract}

\section{RESUMEN}

Submitted: 13/09/2019; Accepted: 04/11/2019

México es considerado uno de los países megadiversos biológica y culturalmente hablando. Los pueblos originarios tienen en su haber múltiples conocimientos que se reflejan en las estrategias de sobrevivencia desarrolladas a lo largo de generaciones, desde el respeto por la naturaleza y la protección de esta, hasta la atención de enfermedades, que forman parte de la conservación de la diversidad biológica. Para comprender y analizar estos procesos, partimos de la etnobotánica a la que hemos integrado la memoria biocultural y el análisis de los procesos de salud/enfermedad/atención como complemento, por lo que estamos presentando un estudio de carácter interdisciplinario en San Marcos Tulijá, municipio de Chilón, Chiapas. Para ello, se realizaron entrevistas semiestructuradas a la comunidad, para documentar los conocimientos locales, la relación con su entorno natural y el uso de algunas plantas consideradas medicinales; además de entrevistas estratégicas a las personas mayores de edad para conocer la historia de la comunidad. Estos conocimientos fueron clasificados y analizados en una base de datos. Los resultados demuestran que los habitantes tienen un alto grado de conocimientos y prácticas médicas, producto de una estrecha relación con su entorno natural, que se refleja en la apropiación física y simbólica del territorio. Se documenta la importancia cultural y médica de estos conocimientos como estrategias de sobrevivencia ante las adversidades político-sociales y de conservación biológica.

Palabras clave: Conocimiento local, Chiapas, plantas medicinales, estrategias de curación, ser humano/naturaleza

\begin{abstract}
México is considered one of the megadiverse countries biologically and culturally speaking. The indigenous peoples have multiple skills under their belts that are reflected in their survival strategies developed throughout generations, from having respect for nature and protecting it to caring for diseases, which are part of the biological diversity. For understanding and analyzing these processes, we started from ethnobotany to which we have integrated the biocultural memory and the medical anthropology as a complement, so we are presenting an interdisciplinary study in San Marcos Tulijá, municipality of Chilón, Chiapas. In order to do this, semi-structured interviews to the community were conducted for documenting the local knowledge, the relationship with their natural environment, and the use of some plants considered medicinal; in addition, strategical interviews were conducted for learning more about the story of the community. This knowledge was classified and analyzed in a database. The results show that the inhabitants have a high degree of medical knowledge and practices, product of a close relationship with their natural environment that is reflected in the physical and symbolic appropriation of the territory. The cultural and medical relevance of this knowledge has been documented as survival strategies in the face of social-political adversities and biological preservation.
\end{abstract}

Keywords: Chiapas, healing strategies, human/nature, local knowledge, medicinal plants.

\section{INTRODUCCIÓN}

México se caracteriza por ser uno de los países con mayor diversidad biológica en el planeta, al ocupar el cuarto lugar (SARUKHÁN et al., 2009); posee además una gran diversidad cultural reflejadas en sus 68 etnias, 11 familias lingüísticas y 364 variantes lingüísticas (INALI, 2008). Se suman los 
diversos conocimientos, prácticas, vestidos y alimentos (LADIO, 2006; GARCÍA, 2007). Los pueblos originarios son la base de la diversidad cultural y de la diversidad biológica en el mundo (MAFFI, 2001; GARCÍA, 2007).

Por ello, a partir de la década de 1980 y 1990 se abre un campo de estudio con el fin de documentar la relación entre la diversidad biológica y la relación con los pueblos originarios: la diversidad biocultural (GUTIERREZ, 2014). Los pueblos originarios tienen una riqueza cultural que se basa en conocimientos adquiridos de sus antepasados, se refleja en el respeto a la naturaleza y contribuye en el cuidado y la preservación de la diversidad natural de su territorio (PORTO, 2006; NEMOGÁ. 2016). Existe una codependencia entre la diversidad biológica y cultural (TOLEDO Y BARRERA, 2008; TOLEDO, 2012). Teniendo como resultado la conformación de una identidad, de tal forma que cada grupo humano crea una imagen de su entorno (TOLEDO et al., 1995; MAFFI, 2001; PORTO, 2006; NEMOGÁ 2016). Para comprender esta integración, Giménez $(2003: 5,9)$ define la cultura como: "la organización social en sentido interiorizado de modo relativamente estable por los sujetos en forma de esquemas de representaciones compartidas, objetivado en formas simbólicas, todo ello en contextos históricamente especificos y socialmente estructurados". En tanto que la identidad la define como "como: un proceso subjetivo y frecuentemente auto-reflexivo por el que los sujetos individuales definen sus diferencias con respecto a otros sujetos mediante la auto-asignación de un repertorio de atributos culturales generalmente valorizados y relativamente estables en el tiempo.

En este sentido, cada uno de sus integrantes desarrolla acciones e interacciones que son captadas, apropiadas y reproducidas como grupo, y pasa a formar parte de su vida cotidiana. Es por lo que autores como Maffi (2001), Toledo y Barrera (2008), Porto (2018) y Nemogá (2018), han abordado el tema de la relación ser humano/naturaleza desde diferentes enfoques, que explican la evolución de las culturas y su diversidad. Integran la importancia de los conocimientos locales como herramienta en la conservación de la biodiversidad y la defensa del territorio. Concepto que resulta estratégica ya que Porto (2018) lo define como el espacio en donde se tiene acceso a los recursos y, es donde se desarrollan actividades cotidianas, sociales, económicas, culturales y simbólicas. Un espacio que puede ser estudiado desde escalas local, regional, nacional e internacional.

Las escalas espacio-temporales facilitan la comprensión de procesos históricos, sociales, políticos, culturales e incluso procesos ecológicos, que influyen en una región y en una población. Los procesos son entendidos "como un hecho no lineal, sino caracterizado por cortes y cambios más o menos violentos según el caso y el momento" (GARCÍA, 2006: citado por VERA Y MARTÍNEZ, 2017: 5). La cultura a su vez también abarca las formas de comunicación, las conductas y normas establecidas por el colectivo, que se refleja en las prácticas, acciones de cuidado y respeto al entorno natural. Se trata de conocimientos basados en experiencias de vida y de un referente simbólico grupal, que da al individuo pautas para adoptar acciones que le permite enfrentar y resolver problemas, que puede incluir la innovación de estrategias que facilite su resolución y que, una vez comprobada su eficacia por el colectivo, sea asimilado poco a poco. Por lo que se enfatiza aquí, que el conocimiento es dinámico y producto de un aprendizaje, así como la búsqueda de resolución de problemas futuros (LIMÓN, 2010; LIMÓN, 2012).

En ese orden, la etnobotánica como disciplina aborda temas relacionados con los conocimientos tradicionales, el uso y manejo de los recursos vegetales y el conocimiento ecológico. Considerando el valor cultural de las expresiones reflejadas en el sentido interiorizado de la naturaleza humanizada a través de mitos que son respetados y son parte de un territorio sagrado y de un universo que permanece en el tiempo (SANABRIA, 2013). De las distintas líneas de aplicación, para este trabajo interesan la flora medicinal.

Para Porto (2006; 2018), la diversidad biológica es parte del desarrollo de los pueblos originarios, ya que ha formado parte de su vida. En ella se han desarrollado estrategias y conocimientos que satisfacen sus necesidades. Por lo que considera que las investigaciones antropológicas, biológicas y geográficas no deberían olvidarse de la dicotomía humano-naturaleza; espacio-tiempo y sujeto -objeto; puesto que se descalificarían los saberes-prácticas de los pueblos originarios que han tratado de defender a lo largo de su historia y donde han generado estrecho vínculo a través del tiempo. Por su parte, Nemogá et al., (2018: 20-24) y Nemogá (2016), proponen una investigación enfocada en la conservación de conocimientos locales como herramienta para la preservación de la diversidad biológica. Además, han llegado a considerar que los pueblos originarios son los principales actores en los procesos de diversificación biológica y cultural. Por lo que es importante analizar el desarrollo local impuesto por las instancias gubernamentales e intereses privados; así como de las prácticas tradicionales que han 
influido en la erosión de la identidad indígena. A raíz de ello, ha propuesto realizar estudios de carácter interdisciplinario, que tomen en cuenta los protocolos comunitarios establecidos por la misma población.

Por su parte, Maffi $(2001 ; 2007)$ se ha enfocado en el análisis lingüístico, cultural, diversidad biológica y en los factores que influyen en la erosión y perdida de los conocimientos indígenas entre generaciones. Considera al lenguaje y comunicación como factores de influencia en la transmisión de conocimientos, practicas locales y regionales. Así mismo analiza el proceso co-evolutivo de las culturas con la diversidad biológica a nivel local, regional y global.

Por ello, los trabajos con enfoque biocultural permiten analizar, comprender y documentar los procesos de diversificación cultural y biológica tomando en cuenta a la población local como sujetos y no como objetos de estudio. Toledo y Barrera (2008) retoman disciplinas como la ecología, geografía, antropología, historia y etnoecología, para el análisis de los conocimientos locales, que los pueblos originarios han adquirido a lo largo del tiempo y que les ha permitido moldear su entorno como estrategia de sobrevivencia. Estos conocimientos se basan en la relación que va más allá de la utilidad, y que incluye una relación directa, prácticas de respeto y emocional con la naturaleza. Con base en estos elementos, proponen la "memoria biocultural" como una forma de abordar la diversidad biocultural. Consideran que los pueblos originarios son los principales actores y por consiguiente bajo su propia cosmovisión, la naturaleza no solo representa la fuente primaria de vida sino también el centro del universo.

Esta propuesta permite comprender la relación del ser humano con la naturaleza, debido a que es la especie con mayor capacidad de moldear la riqueza natural de su entorno adaptándolas a sus necesidades, como complemento de los hábitats originales, donde fortalece lazos de confianza con su entorno, que se deriva del conjunto de conocimientos y prácticas que han adquirido a lo largo de generaciones de manera individual o colectiva, formando una relación dialéctica, puesto que se adapta al mismo al sacralizarla. El estudio de esta relación implica el análisis de la diversidad biológica y cultural; para el primer caso, los autores lo analizan desde cuatro niveles: el de los paisajes, hábitats, especies y genomas; para el segundo caso, los analizan en tres dimensiones: genética, linguística y cognitiva.

La diversidad biológica se constituye por la flora y fauna silvestre, así como de aquellas especies domesticadas, puesto que tienen un rol dentro de los niveles de la diversidad biológica. Por lo mismo, derivado de la amplitud de la diversidad biológica, para este trabajo se considera adecuado solo hasta el nivel de especies. En lo referente a la dimensión genética, el ser humano se ha desarrollado como especie biológica y, en la diversificación de culturas que se manifiestan en grupos étnicos, así como diversas adaptaciones en sitios estratégicos geográficos desarrollando habilidades de reconocer, aprovechar los elementos de la naturaleza y de clasificar, interpretar y comparar procesos del pasado. Abordando de esta forma la dimensión genética.

El lenguaje (dimensión lingüística), parte de la diversidad cultural, con sus distintas lenguas, ha sido la principal herramienta de interacción con otros grupos sociales e incluso con la naturaleza. Ha dado la posibilidad de crear identidades y desarrollar capacidades de comunicación a través de expresiones tangibles e intangibles como creencias, conocimientos, instrumentos, herramientas, arte, arquitectura, vestimentas, música y alimentación. La dimensión cognitiva es por otra parte, una de las más antiguas y poco estudiadas, guarda importantes conocimientos que le ha permitido al ser humano mantener cierta relación de coexistencia en los procesos de adaptación con la naturaleza. Es el resultado de la acumulación de conocimientos, de la interacción colectiva y conserva herramientas de enorme valor y parte sustancial de su identidad; representa conocimientos y creencias integrados en su vida cultural. De deificaciones, o representaciones mágicas de su entorno natural y cósmicos (estrellas, sol y luna). Se caracteriza por los conocimientos y saberes que permite a un grupo moldear las relaciones con su medio físico-geográfico.

En este sentido, los estudios de diversidad biocultural permiten entender y analizar investigaciones sobre la compleja relación del ser humano/naturaleza desde la población que vive en el lugar que la territorializa física y simbólicamente. Por lo que consideramos retomar la propuesta teórica memoria biocultural de Toledo y Barrera (2008) como una oportunidad para analizar esta compleja relación a partir de las plantas que curan ajustándola a la etnobotánica. Por lo anterior, este trabajo está enfocado en las especies vegetales de uso medicinal, considerando a la población local como colaboradores de la investigación. Y a través de ellos, conocer el valor de los recursos vegetales silvestres y domesticados, así también, el uso y manejo de estos. Se complementa y adecua con herramientas de la antropología 
médica para entender el proceso salud/enfermedad/atención; con ello, estos estudios nos permiten tener una investigación más completa y profunda de una población indígena (FREYERMUTH Y SESIA, 2006).

Por otro lado, se busca un diálogo con la población experta en donde el conocimiento tradicional ha sido una de las fuentes primarias de atención a la salud y formas de tratamiento naturales, al emplear los recursos disponibles a su alrededor (PAGE, 1990) para tratar diversos padecimientos, como es la comunidad de San Marcos Tulijá. Presenta características particulares ya que se conforma por habitantes tseltal/chol, con conocimientos en flora medicinal. Los objetivos de esta investigación son identificar las prácticas, creencias y experiencias en el proceso de salud/enfermedad/atención en torno a las plantas medicinales en hombres y mujeres adultas y explicar la relación del ser humano/naturaleza en San Marcos Tulijá, Chilón, Chiapas; contribuyendo con ello a los estudios etnobotánicos.

Algunos estudios indican que los pueblos originarios han desarrollado a lo largo de la historia una gran variedad de saberes relacionados con el uso de la flora, resultado de múltiples formas de apropiación y clasificación del universo vegetal (MALDONADO, 1979). En ese sentido, se tienen datos insuficientes de trabajos que documenta conocimientos en torno a las plantas medicinales y la relación ser humano/naturaleza. Los estudios con este enfoque para la región son los de Mondragón (2014) en la localidad Masojá Shucjá, en el municipio de Tila; Ubiergo et al, (2016) en el pueblo indígena MayaCh'ol (Salto de Agua) en el Valle de Tulijá y, Hernández et al, (2016), en la cabecera municipal de Pantelhó; que no forma parte del Valle de Tulijá.

\section{MATERIAL Y MÉTODO}

\section{Caracterización geográfica e histórica del Valle de Tulijá. Escala regional.}

El Valle de Tulijá se localiza en el norte del estado de Chiapas dentro de las provincias fisiográficas de las Montañas del Norte y Montañas de Oriente (MÜLLERRIED, 1957a). Presenta un relieve variado, formado por sierras o serranías y cerros, separados por valles que toman distintas direcciones con altitudes variadas que van desde los 500 m.s.n.m. hasta 1200 m.s.n.m. Presenta un clima tropical húmedo y conforme aumenta la altitud se hace más templado. Su vegetación se caracteriza por selvas y bosques tropicales pasando por vegetación de selva alta perennifolia, hasta bosques de coníferas, encinos, pinos y angiospermas variadas (MÜLLERRIED, 1957b).

Sus suelos son de tierra rosa laterítica en las partes bajas y suelos amarillos y migajones del grupo laterítico, sin carbonato de calcio, pero con hidrosilicatos e hidróxidos de hierro en las partes altas, en otras partes se observan suelos de colores café y podzólicos en las Montañas del Norte. Por otro lado, las Montañas de Oriente presentan suelos del tipo gley, tierras arcillosas con ciertos hidrosilicatos, del grupo gley y suelos lateríticos en algunas partes como tierra rosa laterítica. En la región se puede encontrar zonas de muchos ríos y arroyos que desembocan en el rio Grijalva. Uno de los ríos más importantes de la región del Valle de Tulijá es el río Tulijá. En cuanto a fauna es posible encontrar jabalí, tapir, venados, diversas especies de aves, serpientes, cocodrilos e insectos; además de felinos como el jaguar y el puma (actualmente con muy pocos ejemplares) y el tigrillo (MÜLLERRIED, 1957b). Por su clasificación socioeconómica el Valle de Tulijá es la Región XIV del estado (GOBIERNO DEL ESTADO, 2013).

Desde mediados del siglo XIX, la cuenca del río Tulijá fue una importante zona maderera, mientras que para el siglo XX, fue el desarrollo chiclero y cafetalero, lo que propició que los pueblos originarios tseltales y choles fueran despojadas de sus tierras y explotados laboralmente para el desarrollo de las actividades de comerciantes provenientes de Tabasco y posteriormente por empresas extranjeras de España, Alemania, Inglaterra y Estados Unidos (LOBATO, 1979; ALEJOS, 2004). El desarrollo de la actividad maderera en el norte y selva de Chiapas tuvo un rápido crecimiento debido a que ofrecía excelentes condiciones para su implementación y, la población local fue la fuerza de trabajo gratuita o semi gratuita que facilitó el desarrollo de estas actividades. Las primeras actividades madereras se desarrollaron en la Selva Lacandona a partir del año de 1859 con Felipe Marín (empresario tabasqueño), con la explotación de caoba y cedro. En 1870, la familia Bulnes, Valenzuela e Hijos, Jamlet y Sastré provenientes de Tabasco establecen modestas monterías al este del Valle de Tulijá. En 1914 se establece una montería en el departamento de Chilón y otra en 1929 (DE VOS, 1988), cuando otras de la región y del Valle de Ocosingo, estaban en decadencia (DE VOS, 2004; VIQUEIRA 2004).

A partir de 1915, las casas madereras empiezan su decadencia y otras cerraron sus puertas, como la Casa Bulnes afectada por la Revolución Mexicana (DE VOS, 1988; 2004). Para el año 1920 la explotación maderera en rollo comienza su decadencia y en enero de 1949 el gobierno federal decide 
ponerle fin a esta actividad económica de más de 70 años (DE VOS, 1988). Sin embargo, en 1951 Maderera Maya S.A abre sus puertas en la región de Palenque, empresa maquillada como mexicana, pero de capital norteamericano, para extraer maderas preciosas, donde los indígenas tseltales y choles fueron nuevamente la fuerza de trabajo propicia para continuar con la extracción maderera (DE VOS, 2004; VIQUEIRA, 2004).

En el año de 1905, en la cuenca del río Tulijá se inicia la explotación de hule con las compañías Agua Azul Magahony y Encanto Rubber Plantation y chicle (ALEJOS, 1996; LEYVA, 2004) por un corto periodo. En ese mismo año se implementan las primeras plantaciones de café en los departamentos de Soconusco y Palenque; y para 1909, la finca más importante en la región Tulijá fue la de El Triunfo propiedad de la empresa German-American Coffee Company en el actual municipio de Tumbalá y la finca Mumunil en Tila del alemán Kortüm, además de otras plantaciones en el municipio de Salto de Agua (ALEJOS, 1996). En el que la población chol y tseltal, fueron nuevamente la fuerza de trabajo disponible avaladas por las autoridades gubernamentales (ALEJOS 2004).

Durante el periodo gubernamental de Lázaro Cárdenas (1934-1940 se da fin a la explotación laboral, los malos tratos y se formaron sindicatos de trabajadores (1936) (BARTRA at al., 2011). En 1939 los campesinos obtuvieron tierras dotadas por este gobierno a través de la reforma agraria cuando se formaron ejidos, que aún persisten en la actualidad (ALEJOS, 1996; 2004; NAVARRO, 2008). Aunque parecieron haber cambiado cosas, un acercamiento más detallado permitió ver como algunos ladinos provenientes de San Cristóbal y de los Altos de Chiapas, se desplazaron a la región e intentaron tomar el papel implementado por los empresarios alemanes y estadounidenses, desatándose con ello, un tipo de violencia diferente donde se mostró el incremento de muertes, de población en las cárceles y desplazamientos forzados (ALEJOS, 2004).

El desplazamiento de poblaciones provocadas por la explotación laboral y el despojo de tierras dio lugar, ante la coyuntura posterior de la Revolución Mexicana, que en esta parte del país (que no vivió propiamente el mismo proceso) se dieran repartos ejidales en el norte de Chiapas, durante el periodo presidencial de Cárdenas. En el Valle de Tulijá, el poblado de San Jerónimo Tulijá obtuvo dotación ejidal, después de varias solicitudes de tierra, con una primera y segunda ampliación entre 1963 y 1983. Se integraron otras comunidades aledañas de población chol y tseltal proveniente de diferentes lugares, donde se presentaron conflictos sociales de lucha por la tierra. Al enterarse que en Tulijá había reparto de tierras, muchas familias llegaron al lugar (NAVARRO, 2008).

La comunidad de San Jerónimo Tulijá es ejemplo de estos desplazamientos, sus habitantes son originarios del barrio de San Jerónimo de la región de Bachajón (LOBATO, 1979). Actualmente es el centro ejidal de San Pedro Tulijá, San Gabriel, Paraíso Tulijá y San Marcos Tulijá. Se fundó en el año de 1963, sin embargo, fue hasta el año de 1965 que se les dota de tierras ejidales, reconociendo a 135 ejidatarios con 5500 hectáreas (DOF, 1965). Posteriormente, ante diferentes solicitudes logran dos ampliaciones ejidales en 1971 y 1984, con un total de 26000 hectáreas, para 532 ejidatarios (NAVARRO, 2008); la comunidad de San Marcos Tulijá, forma parte de la primera ampliación ejidal (DOF, 1971).

En el periodo de 1960- 1984, con el ejido formado, se da entrada a proyectos productivos con créditos bancarios para la crianza de ganados, como resultado del acceso a políticas públicas nacionales (NAVARRO, 2006; 2008) y de partidos políticos, que posteriormente fragmentarían la organización comunitaria ejidal en la región (HERNANDEZ, 2009). Estos cambios en la región facilitaron la ampliación de redes fuera de la comunidad de San Jerónimo, dando como resultado en 1997, el ingreso de plantaciones de palma de aceite (Elaeisguineensis Jacq.) en todo el Valle de Tulijá. Dicho proceso fue promovido por el gobierno federal en 1996 a través del programa de desarrollo de agroecosistemas tropicales y subtropicales para la región sureste. Posteriormente, hasta el 2014, las plantaciones estaban impulsadas por el Programa de Desarrollo Sostenible Integrado y Sustentable (PRODESIS) y era financiado por la Unión Europea (LINARES, 2014). Se trata de proyectos que han fomentado la destrucción de gran parte de la vegetación, la sustitución de la agricultura tradicional, la degradación y contaminación del suelo y de los ríos de la región.

El ejido San Jerónimo se encuentra ubicado dentro del municipio de Chilón, toda vez que forma parte de la región del Valle de Tulijá Tseltal- Ch'ol. El municipio de Chilón se localiza en los límites de las Montañas de Oriente de Chiapas, entre las coordenadas $17^{\circ} 07^{\prime \prime} \mathrm{N}$ y $92^{\circ} 17^{\prime \prime} \mathrm{W}$ a $880 \mathrm{msnm}$. Limita al norte con los municipios de Tumbalá, Yajalón, Tila, Salto de Agua y Palenque; al este y al sur con Ocosingo, y al oeste con Sitalá, San Juan Cancuc, Pantelhó y Simojovel de Allende. Su extensión territorial es de $1682.35 \mathrm{~km}^{2}$, que representa el $12.58 \%$ de la superficie de la región Selva y el $3.29 \%$ de 
la superficie estatal. Presenta un clima cálido húmedo, con una precipitación anual de 1630 milímetros. Su vegetación es selva alta, donde habitan variedad de especies como el amate, caoba, cedro, ceiba, chicozapote, hule y jimba. La actividad económica se basa en la agricultura de temporal y ganadería. Hasta el 2010 tenía una población total de 111554 habitantes, el 54.92\% de los adultos habla alguna lengua indígena (INEGI, 2015). La cabecera municipal cuenta con dos centros de salud, IMSS y SSA. La principal actividad económica es la agricultura y ganadería (CHILÓN, 2015; CONEVAL, 2017).

\section{Escala local}

San Marcos Tulijá es uno de los poblados del ejido que no se han sumado a la siembra y explotación de palma de aceite, decisión tomada entre los pobladores de la propia comunidad; representando un claro ejemplo del cuidado y protección de su entorno, el reflejo de una organización comunitaria y la muestra de apropiación territorial. Los procesos históricos vividos en la región han permeado a los habitantes de la comunidad, y se refleja en la desconfianza hacia personas o grupos ajenos a ello, muestran un amplio recelo ante intereses externos, por lo que consideramos importante respetar los protocolos comunitarios, junto con las decisiones que los ejidatarios toman en su espacio ejidal; lo que permitió generar confianza en toda la comunidad.

San Marcos Tulijá se fundó en el año de 1970, actualmente lo integran 4 familias extensas debido a los lazos consanguíneos y vínculos formados a lo largo del tiempo, pero son de origen tseltal y ch'ol conformadas en 26 viviendas, se ubica al noreste del municipio de Chilón (Figura 1). Tiene una población total de 162 habitantes (80 mujeres y 82 hombres) (INEGI, 2015). Los fundadores de la comunidad fueron el Sr. Manuel N (Chol) y Sr. Andrés N (Tseltal) originarios de Tumbalá y San Gabriel Tulijá respectivamente. Posteriormente arriban dos familias más, provenientes de las comunidades de San Pedro y Paraíso Tulijá. Una de ellas es originaria del municipio de Tumbalá (familia Arcos), hablante de la lengua ch'ol, al igual que los habitantes de San Jerónimo, llegaron en busca de tierras y al darse cuenta de que, el territorio ahora ocupado eran territorios nacionales decidieron establecerse. Las otras 3 familias (Gómez, de San Gabriel; Hernández, de San Pedro Tulijá y; Jiménez de la comunidad de Paraíso Tulijá) son integrantes de la etnia tseltal.

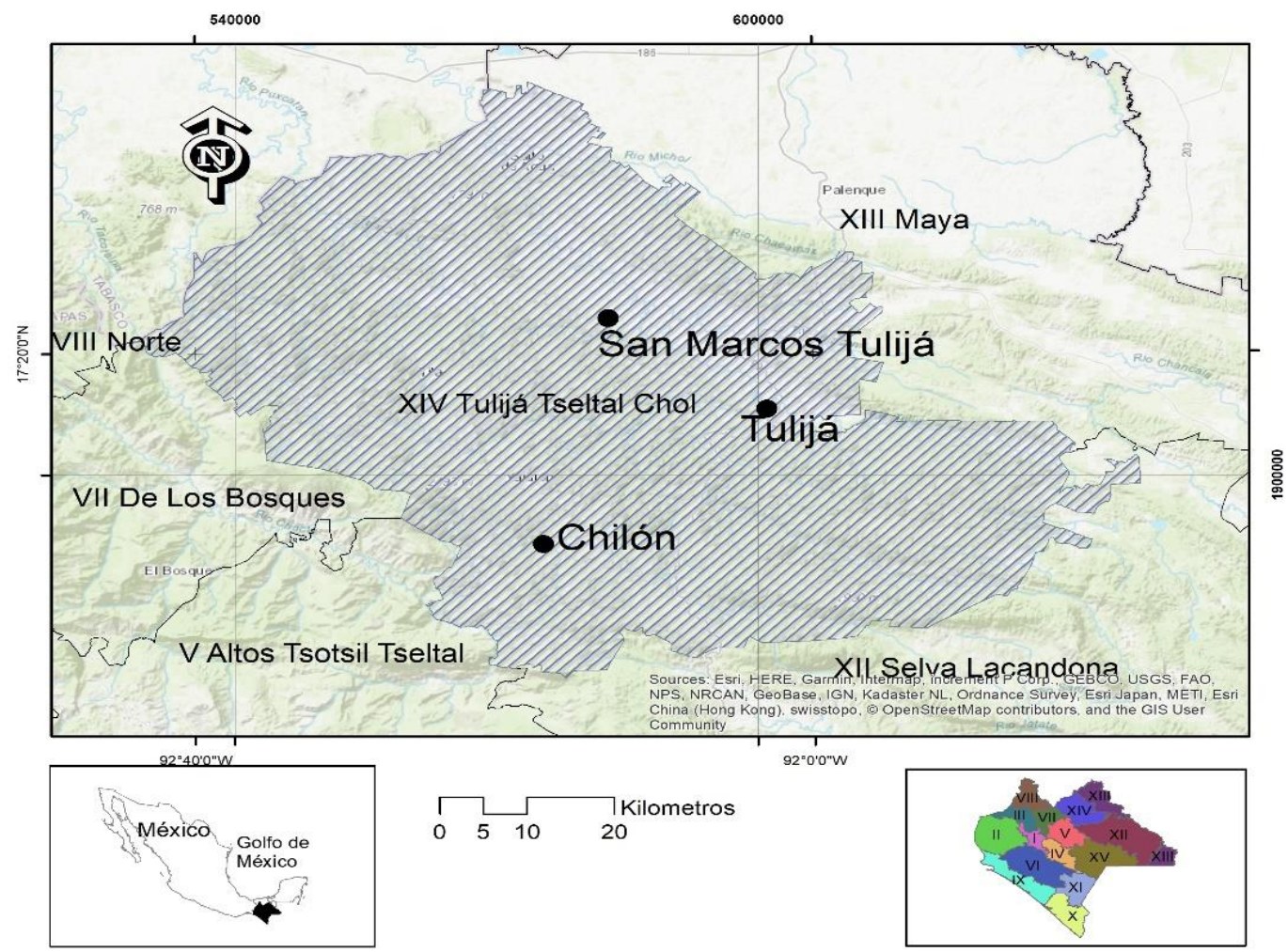

Figura1: Ubicación del municipio de Chilón, dentro del Valle de Tulijá, Chiapas, México. 2019. (Elaboró Rodimiro Ramos Reyes, LAIGE)

El trabajo de campo se realizó durante los meses de mayo y junio de 2018. Se hicieron entrevistas semiestructuradas y la aplicación de una encuesta, en San Marcos Tulijá. En ambos casos se registraron 
datos relacionados con el uso de la flora medicinal, nombre común en tseltal y español, usos, dosis y padecimientos, así como las distintas prácticas médicas en el proceso de salud/enfermedad/atención y de la relación con su entorno que se realizan en la comunidad. También se preguntó sobre la historia de la comunidad, desde su fundación hasta la actualidad. Se tomaron datos morfológicos de los ejemplares y fotografías, no se colectaron ejemplares completos, pero si estructuras reproductivas para su determinación. La determinación de especies se realizó en el laboratorio de Biología Vegetal de la Benemérita Universidad Autónoma de Puebla (BUAP), para ello se usaron claves dicotómicas. La mayor parte de las entrevistas fueron realizadas en lengua tseltal (variante dialectal Tseltal del Norte) y fueron grabadas con el permiso de los entrevistados para posteriormente ser traducidas al español, lo que permitió elaborar una base de datos cualitativos para clasificar la información. Para realizar el trabajo se realizó previo permiso de la autoridad local para plantear el objetivo del trabajo, posteriormente se solicitó permiso a la comunidad en una asamblea para realizar las actividades y la aprobación del trabajo de entrevistas mediante una carta de consentimiento informado de las familias.

\section{RESULTADOS \\ Diversidad biológica (flora)}

Se registraron 35 ejemplares botánicos, los cuales se agrupan en 19 familias, 26 géneros, 28 especies y 2 variedades; así como 6 ejemplares no identificados. Las familias mejor representadas, con tres especies cada una son: Asteraceae y Rutaceae; Lamiaceae, Liliaceae, Piperaceae y Solanaceae con dos especies cada una. En cuanto a géneros, la Familia Asteraceae es la mejor representada con tres géneros y tres especies; los géneros con mayor registro son Piper con tres especies; Citrus y Ocimum con dos especies cada una. De formas de vida, se documentan 20 especies herbáceas seguidas de las arbóreas y arbustivas, con 10 y 3 especies respectivamente. Las especies mejor valoradas con más menciones son Verbena litoralis Kunth con 7 menciones; Tagetes erecta L., Ocimum basilicum var. glabratum Benth y Teloxys ambrosioides (L.) W.A.Weber, con 4 menciones cada una; y con menor mención fueron Allium sativum L, con tres y Piper nigrum Wall., Ruta chalepensis L. y Byrsonima crassifolia Steud, con dos menciones cada una.

Las estructuras vegetales de mayor importancia son las hojas, seguidas de raíces y flores (gráfica 1). De acuerdo con la clasificación de manejo y de categorías de sitios de localización de Toledo et al., (1995) se registraron cinco categorías de grados de manejo domesticadas, semi domesticadas, introducidas, silvestres y protegidas. Donde las especies domesticadas son aquellas que se encuentran en macetas, solares y jardines de traspatio; las semi domesticadas son aquellas localizadas en milpas, caminos y cafetales que cuando se necesitan, saben dónde ubicarlas. Las silvestres son aquellas especies que se encuentran en montañas, selvas o cerros donde es necesario buscarlas para colectarlas y que además dependen de temporadas para su colecta; las especies introducidas se refiere a aquellas que son llevadas a la comunidad desde alguna otra población y que ya las están reproduciendo y son protegidas por la comunidad. Las de mayor número de especies registradas son las domesticadas, seguidas de las silvestres y una especie protegida (gráfica 2).

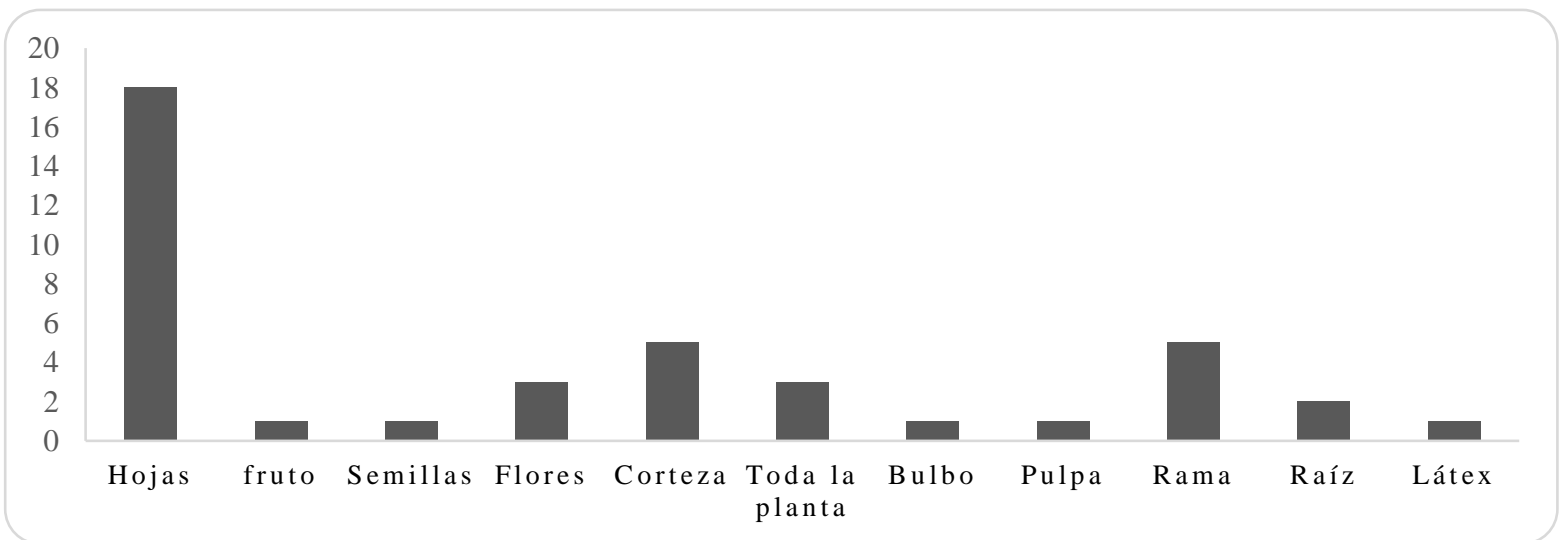

Gráfica 1: Estructuras vegetales de importancia medicinal empleadas en San Marcos Tulijá, Chiapas, México. 2019.

Algunas de esas especies domesticadas con mayor interés son Allium sativum, Tagetes erecta, Ocimun basilicum var. glabratum, Verbena litoralis, Teloxyx ambrosioidesy Artemisia absinthium L. 
Dentro de las especies semidomesticadas se menciona la Arnica montana L. Las introducidas son Thymus vulgaris M. Bieb., Ruta chalepensis y Foeniculum vulgare Hill. La especie protegida que también tuvo mayor mención es Aspidosperma megalocarpon Müll. Arg., debido a que anteriormente la comunidad de San Marcos Tulijá le daba uso frecuente, la población de esta especie empezó a disminuir, por lo que por consenso comunitario decidieron protegerla; la CONABIO la registra como especie amenazada.

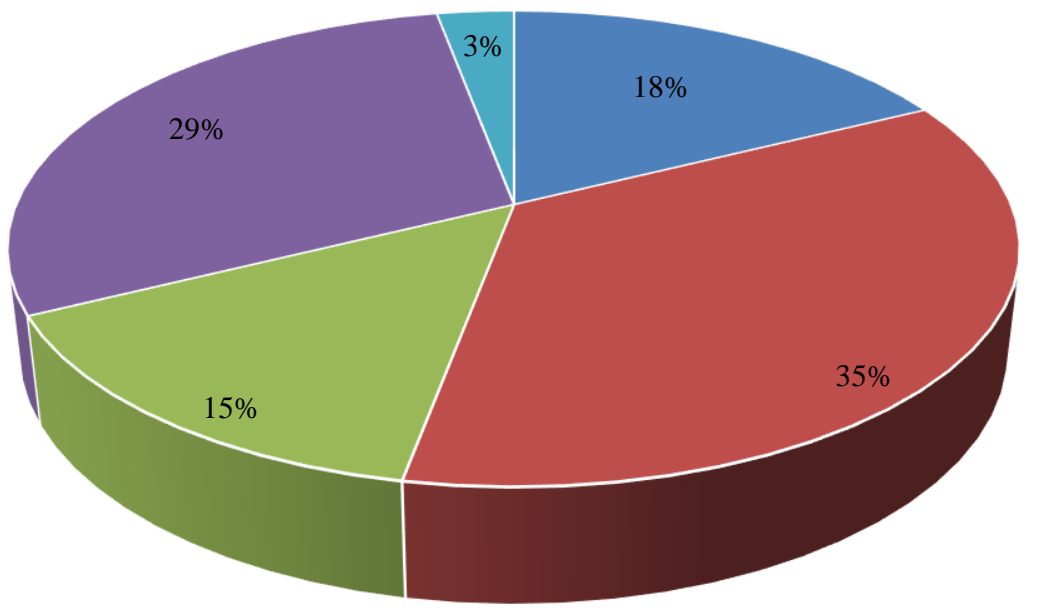

- Semidomesticadas " Domesticadas " Introducidas "Silvestres " Protegidas

Gráfica 2: Porcentaje del grado de manejo de las especies registradas en San Marcos Tulijá, Chiapas México. 2019.

En cuanto a sitios de localización se registran 7 categorías (Gráfica 3), se agregan tres adicionales milpa-cafetal, cafetal-cacaotal y maceta-jardín. La categoría con mayor número de especies registradas es la de maceta con 11 especies, y la de menor número son milpa-cafetal, cafetal-cacaotal y macetajardín.

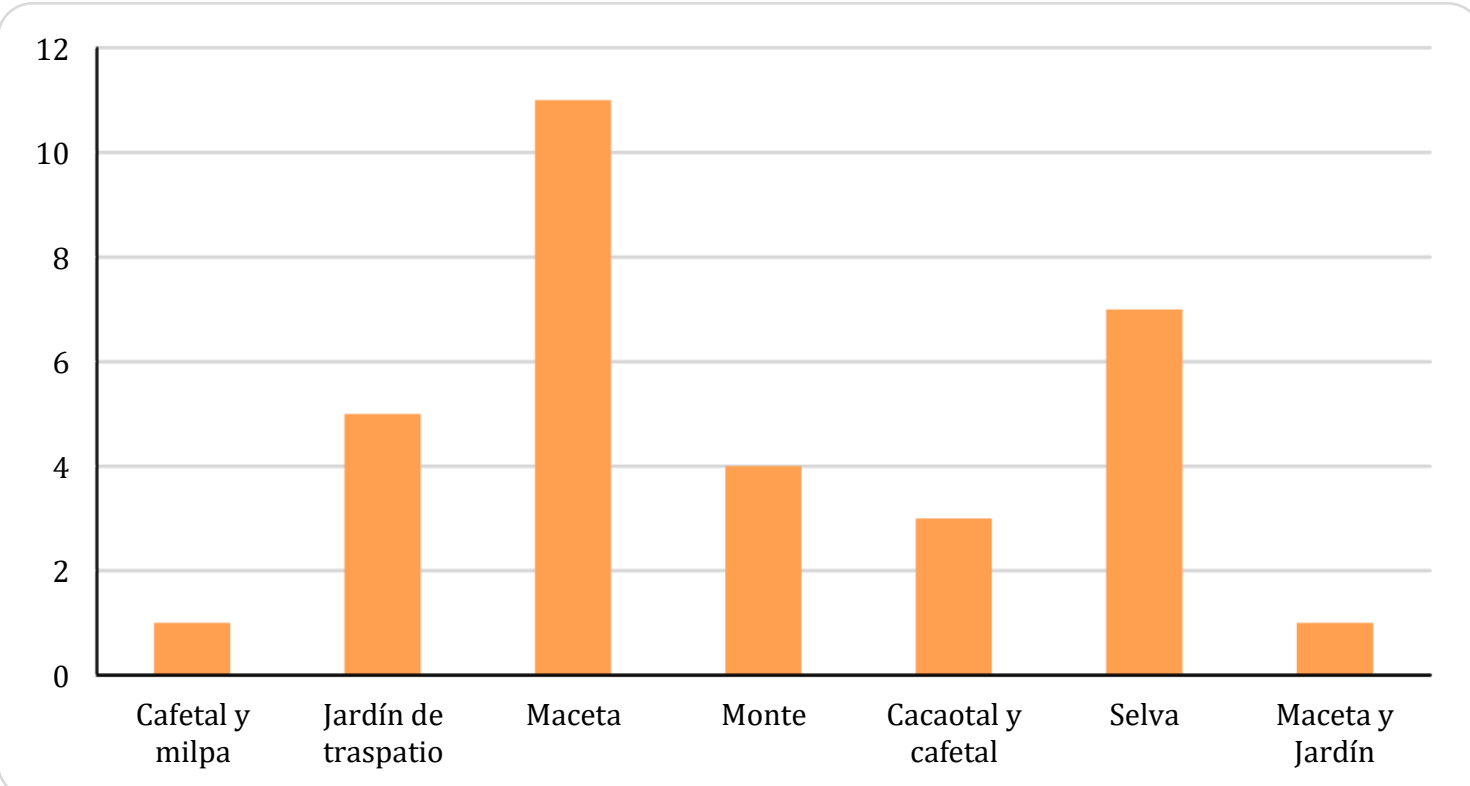

Gráfica 3: Sitios de localización de las especies vegetales medicinales en San Marcos Tulijá, Chiapas, México. 2019 
En el siguiente cuadro (Tabla 1) se detalla la clasificación botánica de las especies registradas en San Marcos Tulijá. En él se observa que la mayoría de las especies son reconocidos (Dimensión genética) por los habitantes, tanto por el nombre en español como en lengua tseltal. Sin embargo, se puede observar que seis de ellas, no tienen nombre en español, sólo se les identifica en su propia lengua.

Tabla 1: Listado de especies vegetales reconocidos con nombre local en lengua tseltal y español. por los habitantes de la comunidad de San Marcos Tulijá, Chilón, Chiapas, México. 2019.

\begin{tabular}{|c|c|c|}
\hline FAMILIA/especie & NOMBRE(S) COMÚN TSELTAL & NOMBRE EN ESPAÑOL \\
\hline \multicolumn{3}{|l|}{ ASTERACEAE } \\
\hline Tagetes erecta $\mathrm{L}$. & Tususnichim & Flor de muerto \\
\hline Arnica montana $\mathrm{L}$. & Chákil & Árnica \\
\hline Artemisia absinthium $\mathrm{L}$. & Ch'ajch'ajlojp', k'anajal & Ajenjo \\
\hline \multicolumn{3}{|l|}{ APOCINACEAE } \\
\hline Aspidosperma megalocarpon Müll. Arg. & Patbajyalte' & Chichi o chiche colorado \\
\hline \multicolumn{3}{|l|}{ ASPHOLEDACEAE } \\
\hline Aloe vera $\mathrm{L}$. & Sábila & \\
\hline \multicolumn{3}{|l|}{ AMARYLLIDACEAE } \\
\hline Allium sativum $\mathrm{L}$. & Axux & Ajo \\
\hline \multicolumn{3}{|l|}{ APIACEAE } \\
\hline Foeniculum vulgare Hill. & Hinojo & Hinojo \\
\hline \multicolumn{3}{|l|}{ CHENOPODIACEAE } \\
\hline Teloxys ambrosioides (L.) Weber. & Kaka'an & Epazote \\
\hline \multicolumn{3}{|l|}{ COMMELINACEAE } \\
\hline Tradescantia spathaceae Sw. & Yaxal maguey & Maguey morado \\
\hline \multicolumn{3}{|l|}{ CRASSULACEAE } \\
\hline Kalanchoe pinnata Pers. & Mala madre & Mala madre \\
\hline \multicolumn{3}{|l|}{ FABACEAE } \\
\hline Mimosa pudica Mill. & K'exawalch'is & No registrado \\
\hline \multicolumn{3}{|l|}{ POACEAE } \\
\hline Cymbopogon citratus Staff & Limón ak & Zacate limón \\
\hline \multicolumn{3}{|l|}{ LAMIACEAE } \\
\hline Thymus vulgaris $\mathrm{L}$. & Tomillo & Tomillo \\
\hline Ocimum basilicum var. pilosum & Spoxilweelil & Albahaca \\
\hline Ocimum basilicum var. glabratum Benth. & Albajaca & Albahaca \\
\hline \multicolumn{3}{|l|}{ MALPIGHIACEAE } \\
\hline Byrsonima crassifolia Steud. & Nans & Nanch \\
\hline \multicolumn{3}{|l|}{ MORINGA } \\
\hline Moringa oleifera Lam. & Moringa & Moringa \\
\hline \multicolumn{3}{|l|}{ MYRTACEAE } \\
\hline Psidium guajava L. & Pata' & Guayaba \\
\hline \multicolumn{3}{|l|}{ PIPERACEAE } \\
\hline Piper nigrum Wall. & Pimienta & Pimienta \\
\hline Piper sp. (L.) & Mumúnjos & No registrado \\
\hline Piper sp. (L.) & Ik'os & No registrado \\
\hline \multicolumn{3}{|l|}{ RUBIACEAE } \\
\hline Hamelia patens Jacq. & Sweelchitam & No registrado \\
\hline \multicolumn{3}{|l|}{ RUTACEAE } \\
\hline Citrus limon (L.) Osbeck & Ya'binalelemux & Hojas de limón \\
\hline Citrus sinensis Pers. & Ya'binalalaxax & Hojas de naranja \\
\hline \multicolumn{3}{|l|}{ SOLANACEAE } \\
\hline Capsicum sp. (L.) & Ya'binal ich & Hojas de chile \\
\hline Solanum torvum $\mathrm{Sw}$. & Tujk'aronch'is & Sosa \\
\hline \multicolumn{3}{|l|}{ VERBENACEAE } \\
\hline Verbena litoralis Kunth. & Yakank'ulub & Verbena \\
\hline \multicolumn{3}{|l|}{ ZINGIBERACEAE } \\
\hline Zingiber officinale Roscoe & Senjible & Gengibre \\
\hline Sin ejemplar para identificar & Chikja'balte' & No registrado \\
\hline Sin ejemplar para identificar & Bak' ijtzal pi' & No registrado \\
\hline Sin ejemplar para identificar & Yisimmamal & No registrado \\
\hline Sin ejemplar para identificar & Otox & No registrado \\
\hline Sin ejemplar para identificar & Mo’te' & No registrado \\
\hline Sin ejemplar para identificar & No regisrtado & Melisa \\
\hline
\end{tabular}




\section{Dimensión lingüística y cognitiva}

San Marcos Tulijá originalmente se formó por dos etnias tseltales y choles; aunque por estrategias sociales y políticas, los segundos se han asimilado a los primeros, actualmente han tejido vínculos familiares. Desde la dotación en la primera ampliación ejidal ocurrida en 1971 (DOF, 1971), queda integrada por cuatro familias extensas. Las familias fundadoras son choles y tseltales, quienes a lo largo del tiempo han logrado integrarse entre sí, aunque los primeros se vieron en la necesidad de aprender un idioma más, el tseltal. Así, algunos de sus habitantes son trilingües, al hablar ch'ol, tseltal y español. Mientras que las tres familias tseltales hablan el español y tseltal, aunque al parecer, solo los más jóvenes. La población mayor de edad es monolingüe.

Ambos grupos son ramas lingüísticas de la lengua maya que han logrado adaptarse a los diversos medios naturales, desarrollando estrategias y medios de sobrevivencia ante adversidades físicogeográficas. Esta adaptación se observa en los lazos familiares que se han generado a lo largo del tiempo; pero además han desarrollado un estilo de vida particular, con una estrategia política y social que les ha servido para la defensa de su espacio, que han territorializado y de su entorno en general. Lo que significa que conocen las características locales y le dan el uso y cuidado que consideran importante para que la naturaleza pueda conservarse, pero también han logrado una apropiación física que comenzó con el reparto ejidal, que provocó que su organización comunitaria los defendiera de intereses extraños. Muchas comunidades indígenas de Chiapas pueden tener una apropiación simbólica del lugar en el que viven, es decir, saben de plantas, para que sirven, cuáles son comestibles y cuáles no, cuáles pueden curarlos, identifican los ciclos agrícolas, las estaciones del año, etc., pero no todos tienen una apropiación física, es decir, tener la posibilidad de decidir qué sembrar, cómo y cuándo, así como poder decidir quién o quiénes son bienvenidos a la comunidad y quién o quiénes no.

La cultura maya ha sido una de las más importantes de México y Centroamérica, de ella se han derivado una diversidad de poblaciones y lenguas indígenas. En el estado de Chiapas se reconocen 12 lenguas indígenas. De acuerdo con el INEGI (2015), seis de ellas presentan el mayor número de hablantes. Entre las que se encuentran el Tseltal (7.5\%), Tsotsil (6.6\%), Ch'ol (3.4\%), Tojolabal (1.3\%), Zoque $(0.8 \%)$ y Mam (0.2\%), (Sic, 2018) (Figura 2). En lo que respecta a la lengua tseltal, presenta cuatro variantes lingüísticas bats'ilk'op o tseltal del occidente, bats'il k'op o tsetal del norte, bats'il k'p o tseltal del oriente y bats'il k'op o tseltal del sur (INALI, 2019). En San Marcos Tulijá se habla la variante tseltal del norte.

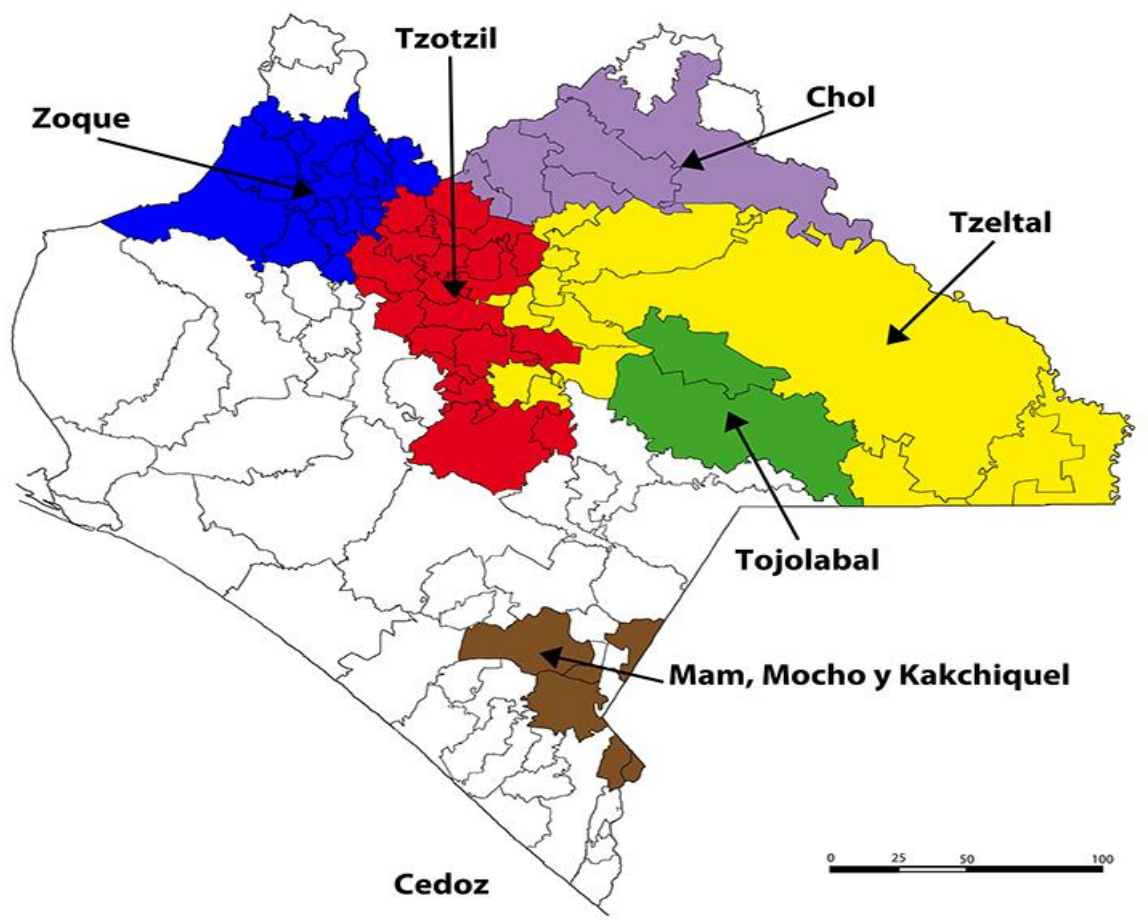

Figura 2: Principales lenguas indígenas predominantes en Chiapas. México. 2019. (Fuente: CEIEG) 
Si bien la linguiística se refiere al lenguaje, a la acción, y a las formas de comunicación, no se limita a ello. Sino que involucra aquello que es reconocido y con un nombre, desde el lenguaje local, que se basa en los conocimientos ecológicos que la población posee (dimensión cognitiva), lo que implica también una forma de apropiación simbólica de su entorno. En ese sentido, la trasmisión de conocimientos no se limita a la comunicación oral, sino a diferentes formas de transmisión de conocimientos, prácticas y experiencias médicas o agrícolas. Del mismo modo, el conocimiento en la atención de la salud se ha reforzado con el contacto del exterior.

La comunidad retoma a las plantas como resultado de un amplio conocimiento de su entorno al darles uso medicinal (tabla 2). Estos conocimientos permiten clasificar y prevenir enfermedades basados en su experiencia de vida, y con ello desarrollar medidas de curación, sumado a las estrategias de prevención como dejar de usar agroquímicos en los cultivos, ya que: "teme yaj tujunntik poxil jamal ta k'altik ya yotses jchameltik" [“usar agroquímicos en las milpas, producen enfermedades"].

Tabla 2: Usos, padecimientos, partes usadas y formas de preparación registradas en San Marcos Tuliijá. Categorías: Ho: hojas, Fl: flor, PC: Plantas completa, Co: Corteza, La: latex, Ra: Ramas, Rz: Raíz, Se: Semilla, Pu: Pulpa

\begin{tabular}{|c|c|c|c|c|}
\hline ESPECIE & PADECIMIENTOS & $\begin{array}{l}\text { PARTE } \\
\text { USADAS }\end{array}$ & DOSIS & PREPARACIÓN \\
\hline Annona montana $\mathrm{L}$. & $\begin{array}{l}\text { Aires en el corazón y } \\
\text { dolor de cabeza }\end{array}$ & Ho & $\begin{array}{l}\text { Un vaso en la mañana y en } \\
\text { la tarde }\end{array}$ & $\begin{array}{l}\text { Hojas licuadas y tomar } \\
\text { como agua de tiempo. }\end{array}$ \\
\hline Tagetes erecta L. & $\begin{array}{l}\text { Calentura y dolor de } \\
\text { cabeza }\end{array}$ & $\mathrm{Fl}$, Ho & Baño tres veces al día & $\begin{array}{l}\text { Se machacan y se usan } \\
\text { como baños, el residuo se } \\
\text { usa como emplaste en la } \\
\text { cabeza. }\end{array}$ \\
\hline $\begin{array}{l}\text { T. ambrosioides (L.) } \\
\text { Weber }\end{array}$ & Vómito y diarrea & Ho & $\begin{array}{l}\text { Todos los días hasta que el } \\
\text { enfermo se cure }\end{array}$ & Hervido para té. \\
\hline T. spathaceae $\mathrm{Sw}$. & $\begin{array}{ll}\text { Sanar } & \text { heridas } \\
\text { diabéticas } & \end{array}$ & Ho & Lavar todos los días & Hervido. \\
\hline A. absinthium L. & $\begin{array}{l}\text { Diarrea, para el } \\
\text { estómago que brinca, } \\
\text { aires en el estomago }\end{array}$ & $\mathrm{PC}$ & $\begin{array}{l}\text { Se toma todos los días } \\
\text { hasta que el enfermo se } \\
\text { cure }\end{array}$ & Hervido \\
\hline K. pinna Pers. & $\begin{array}{l}\text { Tratamiento para } \\
\text { embazarse }\end{array}$ & Ho & $\begin{array}{l}\text { Se toma como agua de } \\
\text { tiempo. }\end{array}$ & Hervido \\
\hline M. pudica Mill. & Dolor de cabeza & $\mathrm{Ra}$ & Todos los días hasta curar & $\begin{array}{l}\text { Licuado con hojas de flor } \\
\text { de muerto, albacaha y } \\
\text { verbena }\end{array}$ \\
\hline C.citratus Staff. & Dolor de garganta & $\mathrm{PC}$ & Todos los días hasta curar & Hervido \\
\hline T. vulgaris L. & Diarrea, vómito & $\mathrm{Ra}$ & Todos los días hasta curar & Hervido \\
\hline M. oleifera Lam. & Controla la diabetes & Ho, Fl & Todos los días & Licuado \\
\hline A.vera $\mathrm{L}$. & $\begin{array}{l}\text { Gastritis y ardor en el } \\
\text { estomago }\end{array}$ & $\mathrm{Pu}$ & $\begin{array}{l}\text { Durante tres días en las } \\
\text { mañanas y tardes }\end{array}$ & Licuado con agua. \\
\hline H. patens Jack. & $\begin{array}{l}\text { Dolor de estómago, } \\
\text { picadura de serpiente y } \\
\text { forraje para cerdos }\end{array}$ & Ho & Todos los días & $\begin{array}{l}\text { Hervido. Para la picadura, } \\
\text { se machacan las hojas y se } \\
\text { usa como emplaste. }\end{array}$ \\
\hline C. limon (L.) Osbeck & Tos & Ho, Fr & Todos los días & $\begin{array}{l}\text { Hervido y se mezcla con } \\
\text { hojas de naranja y miel o } \\
\text { azúcar. }\end{array}$ \\
\hline Piper sp. (L.) & Dolor de huesos & Ho & Se usan durante 15 días & $\begin{array}{l}\text { Hervido y se mezcla con } \\
\text { patbajyalte' }\end{array}$ \\
\hline F. vulgare Hill & $\begin{array}{l}\text { Para calmar la tristeza, } \\
\text { dolor del corazón }\end{array}$ & $\mathrm{PC}$ & $\begin{array}{l}\text { Todos los días o cuando } \\
\text { hay malestar }\end{array}$ & $\begin{array}{l}\text { Hervido y se mezcla con } \\
\text { tortilla quemada. }\end{array}$ \\
\hline V. litoralis Kunth. & $\begin{array}{l}\text { Calor y dolor de } \\
\text { estómago }\end{array}$ & $\mathrm{Ra}$ & Una vez al día & Licuado \\
\hline Capsicum sp. (L.) & $\begin{array}{l}\text { Aires en el cuerpo y } \\
\text { dolor de cabeza }\end{array}$ & Ho & Todos los días & $\begin{array}{l}\text { Se mezcla con hojas de flor } \\
\text { de muerto, albahaca } M \text {. } \\
\text { púdica }\end{array}$ \\
\hline
\end{tabular}

A pesar del difícil acceso a la comunidad, se han generado redes de comunicación e intercambio de conocimientos interpersonales e incluso el uso del internet por parte de la población más joven, les ha permitido consultar diversas formas de curación e introducirla. Tal es el caso de la moringa, que se introdujo a la comunidad para curar la diabetes. Actualmente se tiene el registro de dos personas adultas con este padecimiento. Los familiares más jóvenes buscaron dar respuesta a la enfermedad a partir de 
la búsqueda por internet, encontrando a la moringa, una planta que no es de la región, ni del país, pero se está sembrando en varias partes de la región sureste. La persona enferma, al enterarse de la planta corroboró su efecto con vecinos del poblado de San Jerónimo y regreso a San Marcos con la planta, la sembró y la usa en forma de té y como agua de tiempo. Con ello, queremos señalar que el conocimiento es dinámico. Para la comunidad se trata de una nueva enfermedad que está siendo atendida utilizando distintos medios de comunicación tanto digital, como haciendo uso de sus redes sociales de apoyo que trascienden su propia comunidad.

En San Marcos Tulijá se observa un alto grado de conocimientos de plantas medicinales ya que reconocen a todas las especies con un nombre en tseltal y español, pero también especies nombrados solo en lengua indígena como ik'os, chikjabalté, bak' ijtzal pi, yisim mamal, otox y mo'té (especies en tseltal, sin nombre en español registrado), dichas especies son silvestres y se localizan en selva principalmente. Por lo que la interacción de ambos grupos indígenas ha enriquecido el conocimiento mediante el intercambio, y a su vez, se ha fortalecido y revalorizado entre generaciones.

Por otra parte, la relación con su entorno físico-geográfico se refleja en las distintas formas de comunicación; los rituales son una forma de interacción con su medio ya que mediante ello "yax k'opojotik ch'ulumch'ulk'inal, kalbetikwokol, sokyaj xi' k'extik, yu'unma' xlajweelkuch'eltik" ["se habla con la madre tierra, se le pide que nos permita cosechar otro año más"], y a las montañas "ya kalbetik wokol yu'un ya ya'k tal ja'al yu'un k'altik" ["se le pide que traiga agua, para la milpa, que no haya sequía"], para obtener buenas cosechas en el año. Estos lenguajes de comunicación les ha servido para establecer vínculos con la naturaleza, si bien es cierto que a lo largo de la historia ha habido una mezcla sincrética de prácticas ancestrales y de la religión católica. En la práctica, ambas subsisten y en ocasiones se entremezclan los rezos católicos y la enunciación de algunos salmos, mientras se aplican las plantas al enfermo.

En ese orden de ideas, se registraron padecimientos comunes como dolor de cabeza, dolor de estómago, vómito, diarrea, tos, gripa, dolor de hueso y calentura; por lo que para cada padecimiento se usan plantas específicas, aunque también pueden ser sustituidas por otras o mezclarlas para hacerlas más efectivas. Las especies que se mencionaron para el dolor de estómago, para enfriar el estómago, quitar los aires en el corazón y calmar la tristeza se usa yakan k'ulub o verbena ( $V$. litoralis), pueden ser combinada con otras especies como tujk'aron ch'is (Mimosa pudica L.) y ruda (R. chalapensis) para el tratamiento de la calentura y dolor de cabeza.

Algunas especies registradas en este trabajo son para el tratamiento de padecimientos como la tos (axux, yabinal elemux, yabinal alaxax y otox). Para el dolor de cabeza (tusus nichim (flor de muerto), se utilizan 13 hojas de tusus (flor de muerto), albahaca, ruda, yakan k'ulub (verbena), mumum jos (sin nombre en español registrado), k'exawal ch'is (Mimosa púdica) y jengibre. Para el dolor de estómago se emplean 13 hojas de yabinal ich (hojas de chile), tusus nichim (flor de muerto), albajaca (albahaca), ruda, k'exawal ch'is (Mimosa púdica) y yaka k'ulub (verbena). Por otra parte, algunos padecimientos causados por factores como la brujería (pukujil chamel [mal echado]), que no pueden ser tratados con medicamentos farmacéuticos ni por médicos, sino por personas que tienen el don de revertirlo, conocidos como poxtawanejeti k["curanderos"]. En San Marcos Tulijá, se encuentran dos curanderos quienes no concedieron entrevistas, ambos representantes de cada una de las etnias.

En la comunidad, se registraron otras formas de curación, las limpias o también llamadas "rameadas". Estas prácticas médicas se emplean para el dolor de cabeza causada por la vergüenza, y se utiliza chijilté (especie sin nombre en español registrada), agua y algunas oraciones. También se usa albahaca, que quita el sikil ik' ["aire frío"] del cuerpo acompañados con oraciones bíblicas. Por otra parte, las enfermedades tienen un origen caliente y frío, las cuales son provocadas por las actividades físicas o por la naturaleza. Los conocimientos y saberes de la comunidad reflejan una relación muy estrecha con su entorno físico-geográfico, puesto que el respeto hacia el "ch'ul lum, ch'ul k'inal" ["madre tierra"] ha sido el vínculo más importante que une a la población con su entorno y como una forma de prevenir enfermedades, que se ha transmitido a lo largo de generaciones. La población local tiene un amplio conocimiento de plantas y las que sirven para curar. En ese trabajo solo se documenta una parte.

\section{DISCUSIÓN}

El estado de Chiapas se caracteriza por ser uno de los estados con mayor diversidad, no solo en especies silvestres, sino también de aquellas donde la población ha intervenido en su distribución y diversificación y que representa una importancia económica, ecológica y cultural (CONABIO, 2013). 
Esta diversidad también se muestra en la riqueza florística de una región geográfica, a nivel regional y local. El Valle de Tulijá presenta una amplia diversidad biológica y riqueza cultural. A pesar de las pocas especies recolectadas, en San Marcos Tulijá se registraron 19 familias botánicas registradas, 26 géneros, 28 especies, 2 variedades y 6 ejemplares no identificadas; se registran dos variedades; menor número de especies con respecto a las reportadas por Ubiergo et al., (2016), en varias comunidades de población Maya Chol, del municipio de Salto del Agua de la misma región donde registran 55 especies medicinales. La susceptibilidad de los habitantes y el tiempo de trabajo de campo pudieron influir en el menor número de registro de especies. De estas se observa que las familias mejor representadas son Asteraceae y Rutaceae. Sin embargo, Asteraceae es una de las más reportadas y distribuidas ya que se registra para diversas regiones en trabajos hechos por Hernández et al., (2016); Levy Tacher (2006); Pérez-Farrera et al., (2004) y Ubiergo (2016); sumado a ello, se registran diversas formas de vida como las herbáceas con el mayor número de especies.

La familia Asteraceae es una de las más estudiadas y de las mejor representadas en cuanto a géneros y especies, contribuyendo a la riqueza a nivel global, regional y local (VILLASEÑOR, 1993). La influencia del ser humano en la diversidad se refleja en el 35\% de especies domesticadas y $65 \%$ de vida silvestre, ligeramente similares a los reportadas por Ubiergo et al., (2016). Es lógico pensar que, al ser una zona de transición de dos montañas como la de Oriente y del Norte, se esperaría una riqueza en cuanto diversidad de especies. Pero debido al recelo que muestran sus habitantes hacia personas ajenas a la comunidad, no fue posible colectar más ejemplares.

Desde la formación de la comunidad de San Marcos Tulijá, ha habido una constante interacción y adaptación entre choles y tseltales, como estrategia de defensa de su territorio, además de una interacción de conocimientos. Maffi (2005) señala que la lengua es uno de los medios importantes para la transmisión de conocimiento entre las diferentes generaciones. Y esto se observa en lo que señala un integrante de la comunidad de San Marcos Tulijá:

“ya yi'ch smajtan al nich'anil, mach'a tulan yo'tan"

["a aquellas personas o integrante de la familia que tenga la capacidad o persona especial digna de heredar los conocimientos que tienen los abuelos"] o bien en ocasiones, de forma escrita.

Esta apropiación física y simbólica de su entorno se refleja en las especies vegetales que se emplean en el tratamiento de diversos padecimientos, pues la mayoría de estas especies cuentan con un nombre local y en español. En ese sentido, la población manifiesta un alto grado de conocimientos en torno a las plantas de uso medicinal, ya que la población identifica padecimientos que:

\section{Los “jchameletik, ma'xu'spoxtabesva o ma'vax lekub tadoctoretik" \\ ["los doctores no son capaces de curar"].}

La población acude a estos recursos naturales como una forma de curar sus enfermedades. Por lo tanto, el tratamiento de enfermedades son conocimientos que los antepasados han transmitido a las nuevas generaciones y han dado lugar a una forma de apropiación de los recursos naturales. El uso de plantas medicinales es un claro ejemplo de estos conocimientos y ha representado una estrategia y herramienta de salud de fácil acceso para la población debido a las precarias políticas de salud que han existido en las comunidades indígenas, y que se ha agudizado con la actual fase neoliberal del capitalismo. Por lo que, de acuerdo con Guzmán- Rosas y Kleiche-Dray (2017) es importante reconocer la diversidad cultural indígena, sus conocimientos, prácticas médicas, formas de relación con su entorno natural y su valor cultural deben ser incluidas en las políticas públicas del estado mexicano en lo que respecta a la salud, economía, agricultura y educación, entre otras.

Con respecto a las formas simbólicas, podemos mencionar el número 13. Para los tseltales del occidente también representa un símbolo importante en las prácticas religiosas, ya que es parte de su cosmovisión. Page-Pliego (2010), ha reportado que los adultos mayores del municipio de Oxchúc ofrendan al santo patrono Santo Tomás, en el que se encienden 13 velas durante cuatro días y, con ella 13 botellas de aguardiente, mientras se ayuna durante estos días. A su vez, en Bachajón, los curanderos emplean 13 ramas de chijilté (sin nombre en español registrado) para las limpias o rameadas. Este número corresponde al calendario maya y está relacionado con los ciclos agrícolas, pero también se relaciona con las entidades que forman parte del universo y de la cosmovisión maya. Aunque actualmente, las nuevas generaciones desconocen el origen de este número y de otras prácticas rituales siguen implementando algunas de ellas. 
Por otro lado, existe una clasificación de enfermedades frías y calientes que se entienden como el origen de los padecimientos. Las enfermedades frías cómo la tos y la gripa se originan a partir del contacto constante con el agua fría (manantial, ríos), por lo que regularmente se contrarresta con medicinas "calientes", como el axux (ajo), té de ya 'binal elemnux o alaxax (hoja de limón o naranja). Las enfermedades calientes, se originan a partir de actividades físicas como el trabajo en el campo, entre ellas, dolor de rodilla o huesos en general, por lo que al:

"teme k'ixin jwinkileltik y yax ochat ta sikil ja', ya yuts'inotik, ya stsakotik, chamel" ["meterse a bañarse al río con el cuerpo caliente, choca el frio con el calor del cuerpo"].

Para evitar estos padecimientos se espera a que disminuya la temperatura del cuerpo, y se trata con pat baj yalté (especie sin nombre en español registrada) en agua caliente como baño. Se intenta evitar el choque de temperaturas, como forma de prevenir estos padecimientos. Estos datos, también son reportados para el municipio de Oxchuc por Page-Pliego (2010).

Un padecimiento común entre las poblaciones indígenas católicas es el "pukujil chamel" ["mal echado"] y aquellos originados por el castigo divino, documentado en la comunidad tseltal de Oxchuc, por Page-Pliego (2010). Para tratar el mal acuden con la persona que "spostawanej" ["sepa curar"] y que pueda prevenirlos; también se realizan rituales para agradecer o pedir a la"ch'ul lum, ch'ul k'inal" ["madre tierra"] a través de oraciones para que "ma' xlaj muk'ul ja'etik" ["no desaparezca el manantial o los ríos"], o que con las aguas no se enferme la familia.

También existe una presencia de seres sobrenaturales como el lab y ch'ulel ["nahuales"] documentadas por de la Garza (2012) en la comunidad tseltal de San Juan Cancuc Chiapas y, en la península de Yucatán donde se mencionan a las montañas, ríos y cuerpos de agua en las oraciones para curar u ofrendar a la tierra. Se trata de una forma de comunicación y sobre todo de establecer contacto con la naturaleza (VOGT, 1979)

Por otro lado, la disminución o la negativa del uso de agroquímicos en los cultivos representan una forma de prevención y de cuidado que se le debe dar a la tierra. Así como el rechazo a la plantación de palma de aceite, como señala un habitante de San Marcos Tulijá.

“Ma ayuk mach'a stsun'oj palma, ya yuts'in lum k'inal, ma ayuk bin yan, yax kol yu'un, ma' xkol ixim, chen'ek, itaj, ja ya kilkotik ta Rio Jordan, puro ja sts'unojik, laj yu'un ixim, o yas sts'unik chenek, pero ma 'ba xkolix, yas lajin abono."

["Nadie siembra palma, porque degrada el suelo, le resta abono al suelo, y ya no crece maíz, frijol o verduras. Nos damos cuenta por las personas de Río Jordán, casi todos tienen palma y ya no tienen maiz, ni frijol. Si puedes sembrar, pero no crece nada”].

Esto refleja un amplio conocimiento ecológico, de respeto, cuidado de la naturaleza y de los suelos; con ello sumado al conocimiento del uso de plantas medicinales es una forma de apropiación física y simbólica de los recursos y de su territorio en general, que va más allá de sus límites al responder a una serie de procesos históricos de desplazamientos. La población identifica plantas que pueden estar más allá de sus límites ejidales, porque conocen una amplia área, que no se circunscribe a las tierras ejidales o de la comunidad, se explica precisamente por los desplazamientos a los que se vieron obligados década atrás y como resultado la formación de una comunidad integrada por familias provenientes de diferentes lugares en búsqueda de tierras. Es probable que exista un sincretismo de conocimientos sobre las plantas y de posibles variantes en la cosmovisión maya de estos dos grupos étnicos. La apropiación simbólica ocurre precisamente cuando hacen uso de los recursos de la tierra para resolver su propia sobrevivencia, o por la identificación de lugares sagrados, la presencia de entidades relacionadas con la naturaleza, nada de lo que ocurre en su entorno es ajeno, pues tiene un significado e importancia para ellos.

La interacción entre tseltales y choles ha fortalecido y enriquecido estos conocimientos manteniéndolos vigentes en las nuevas generaciones, a pesar de las condiciones actuales de globalización y de diversos factores socio- políticos. Oviedo et al., (2007) y Ramírez (2007) señalan que la implementación de políticas públicas homogéneas en poblaciones indígenas, así como los desplazamientos forzados (VILLAFUERTE y GARCIA, 2014) pudieran ser factores que fracturen estos conocimientos. Sin embargo, en San Marcos Tulijá se observa que la interacción de la población con su entorno físico-geográfico se ha fortalecido; además ha propiciado la conservación y el cuidado de la naturaleza basándose en sus conocimientos sobre ella. La dinámica histórica de maltrato, robo de tierras, explotación y búsqueda de nuevas tierras, junto con la dotación ejidal dio lugar a una organización 
comunitaria en defensa de estas, territorializando un espacio que por derecho les pertenece y que se circunscribe a San Marcos Tulijá. Es aquí donde podemos referirnos a una apropiación física. Una territorialización que la población de San Marcos Tulijá ha construido. Y que desde afuera podremos entenderlo con los protocolos comunitarios; es decir, para visitar San Marcos Tulijá se debe respetar los códigos establecidos por ellos.

\section{CONCLUSIÓN}

En San Marcos Tulijá se registra una gran diversidad biológica, el 35\% de las especies son domesticadas y el 29\% son silvestres. Esto indica que existe una gran influenza de la población en esta diversificación, y la preferencia por la accesibilidad de las plantas en el hogar. Se observa que las especies de mayor importancia en cuanto a uso se refiere son $V$. litoralis. $T$. erecta y $O$. basilicum var. glabratum. Además, se registra una especie protegida A. megalocarpon o chiche colorado y, suponemos que es la misma registrada por la CONABIO en la categoría de especie amenazada. La interacción tseltal- chol, ha fortalecido y diversificado estos conocimientos. Sin embargo, no se limitan a lo local sino a una región más amplia, debido a procesos históricos de desplazamientos que les ha permitido un conocimiento más amplio y un sincretismo de este, que los ha llevado a una forma de apropiación simbólica y a una defensa del lugar donde viven. Territorializándolo a partir de una organización comunitaria férrea que tiene como interés decidir lo que siembran y lo que comen; así también de cuidar y proteger a la naturaleza que, en una relación dialéctica, les permite cuidarse a ellos mismos. Una naturaleza sana permite que las plantas estén sanas y los puedan curar de posibles enfermedades; es decir, de una naturaleza que les proporciona su propia sobrevivencia.

La defensa del territorio, de conocimientos, prácticas y experiencias culturales de los pueblos originarios se basa en una serie de procesos históricos, políticos y sociales tanto locales, como regionales y nacionales en donde el Estado ha jugado un papel importante con la implementación de políticas públicas homogéneas o de influencia extranjera basada en una economía neoextractivista, donde no se respeta o considera a las comunidades indígenas que durante mucho tiempo han conservado el espacio donde viven. Lo que ha quebrantado la relación y ha alimentado la desconfianza de los pueblos originarios hacia el Estado y con todo aquel que pretenda imponer decisiones.

Por otro lado, la academia también ha fomentado a que las poblaciones originarias no colaboren en las investigaciones antropológicas y biológicas, pues algunos se han visto involucrados en asuntos de biopiratería, o no reconocen a estos pueblos como los dueños de su conocimiento, de prácticas y de los elementos culturales que los identifican. Por lo que los académicos deberían jugar un papel importante y colaborar con las poblaciones indígenas, considerarlos como sujetos y colaboradores de investigación y no como objetos de estudio.

La memoria biocultural como herramienta teórica permite analizar los conocimientos ecológicos de conservación y protección de la naturaleza, así como del cuidado de su salud presentes en una población como San Marcos Tulijá donde se refleja con las prácticas agrícolas tradicionales, la negativa al uso de agroquímicos y el rechazo de proyectos productivos como la palma de aceite para evitar la fragmentación del suelo y algunas enfermedades. Este estudio de carácter interdisciplinario permite una mejor comprensión del porqué y cómo existe una mayor conservación de la diversidad biológica en espacios cuidados y protegidos por los pueblos originarios de México y del mundo. Finalmente, los estudios del proceso salud/enfermedad/atención y la etnobotánica en ciertos momentos parecen abarcar el mismo campo; sin embargo, son distintos enfoques pero que a veces se entremezclan; por lo que con la memoria biocultural la etnobotánica se fortalece al darle una mayor profundidad en la comprensión social.

\section{AGRADECIMIENTOS}

Los autores agradecen al Consejo Nacional de Ciencia y Tecnología (CONACYT) por el financiamiento para la realización de la presente investigación, al Colegio de la Frontera Sur (ECOSUR); a los habitantes de San Marcos Tulijá por su valiosa participación; al laboratorio de Biología Vegetal de la BUAP; a la Dra. Gabriela Vera, Hilda Cruz y Eber Eduardo Hernández, que apoyaron en la realización de entrevistas los días del 22 al 24 de mayo de 2018; al Dr. Rodimiro Ramos (LAIGE, Ecosur) por su colaboración en la elaboración de los mapas; a la Dra. Rosa Andrés y MC. Ricela Jano por su apoyo en la determinación de ejemplares. 


\section{REFERENCIAS}

ALEJOS- GARCÍA, J. Dominio extranjero en Chiapas el desarrollo cafetalero en la Sierra Norte.

Mesoamérica, (32), 283-298. 1996.

ALEJOS- GARCÍA, J. Los choles en el siglo del café: estructura y etnicidad en la cuenca del río

Tulijá. In J.P. VIQUEIRA y M. H. RUZ (Eds.), Chiapas. Los rumbos de otra historia (p. 508).

México: Instituto de Investigaciones Filosóficas/CIESAS/UNAM. 2004.

BARTRA -VERGÉS, A: COBO, R.; PAZ -PAREDES, L. La hora del café: dos siglos a muchas voces. (R. Becerra, Ed.) (Primera ed). México D.F: Trazos, consultoría editorial. 2011. 238 p. CHILÓN,
$\mathrm{H}$.
A. Chilón.
Disponible
en:

http://www.inafed.gob.mx/work/enciclopedia/EMM07chiapas/municipios/07031a.html. 2015. Acceso: 4 ene 2019

CONABIO. La biodiversidad en Chiapas. Estudio de Estado. Vol. I. (A. Cruz Aragón, E. D. Melgarejo, F. Camacho Rico, \&K. C. Nájera Cordero, Eds.) (Primera Ed). México.2013.

CONEVAL/CONEVAL, Secretaría de Desarrollo Social. Informe anual sobre la situación de

$\begin{array}{llllll}\text { pobreza } & \mathbf{y} & \text { rezago } & \text { social. } & \text { Disponible }\end{array}$
https://www.gob.mx/cms/uploads/attachment/file/32820/Chiapas_031.pdf . 2017. Acceso: 4 ene 2019.

DE LA GARZA, M. Sueño y éxtasis. Visión chamánica de los nahuas y los mayas. México: Universidad Nacional Autónoma de México/Fondo de Cultura Económica.2012.330 p.

DE VOS, J. Oro verde: La conquista de la selva Lacandona por los madereros tabasqueños, 1822-1949.México: Gobierno del estado de Tabasco /Fondo de Cultura Económica.1988.330 p.

DE VOS, J. El Lacandón: una introducción histórica. In J. P. Viqueira \& M. H. Ruz (Eds.), Chiapas. Los rumbos de otra historia. México: Instituto de Investigaciones Filosóficas /CIESAS/UNAM. 2004. $508 \mathrm{p}$.

[DOF]. DIARIO OFICIAL DE LA FEDERACIÓN. 22 de octubre de 1965. México D.F. Diario Oficial de la Federación. 1965.

[DOF]. DIARIO OFICIAL DE LA FEDERACIÓN. 2 de octubre de 1971. México D.F. Diario Oficial de la Federación. 1971.

FREYERMUTH, G.; SESIA, P. Del curanderismo a la influencia aviaria. Viejas y nuevas perspectivas de la antropología médica. Desacatos, 20, 9-28. 2006.

GARCÍA -AGUIRRE, M. A. A. Conocimiento tradicional de los pueblos indígenas de México y recursos genéticos. Comisión Nacional para el Desarrollo de los Pueblo Indígenas 1-60. 2007.

GIMÉNEZ, G. La cultura como identidad y la identidad como cultura. Instituto de Investigaciones Sociales. UNAM, 1-27. 2003

GOBIERNO DEL ESTADO. Programa regional de desarrollo 2013-2018. Región XIV Tulijá Tseltal- Chol. Tuxtla Gutiérrez, Chiapas, México.2013.

GUTIÉRREZ-SANTILLÁN, T. V. Diversidad y especies bioculturales clave: una nueva perspectiva de conservación. Bioma, 19(2),57-66. 2014.

GUZMÁN-ROSAS, S. C.; KLEICHE-DRAY, M. La inclusión del conocimiento tradicional indígena en las políticas públicas del Estado mexicano. Gestión y Política Pública, 26(2), 297-339. 2017.

HERNÁNDEZ ALCÁZAR, J. A.; CRUZ CRÚZ, C.; GARCÍA MARTÍNEZ, R.; JESÚS, G. B. E. DE URBINA ROJAS, F. K.; RODRÍGUEZ ESCOBAR, J. E. Plantas utilizadas por médicos tradicionales de la cabecera municipal de Pantelhó, Chiapas, México. Lacandonia Revista de Ciencias de la Unicach, 10 (1),29-36. 2016.

HERNÁNDEZ -ROMÁN, M. C. Representaciones sociales de la educación en San Jerónimo Tulijá. [Tesis de Maestría]. El Colegio de la Frontera Sur. 2009.

[INEGI], INSTITUTO NACIONAL DE GEOGRAFÍA Y ESTADÍSTICA. Principales resultados de la encuesta intercensal. México. 2015.

[INALI], INSTITUTO NACIONAL DE LENGUAS INDÍGENAS. Catálogo de las lenguas indígenas nacionales: variantes lingüísticas de México con sus autodenominaciones y referencias geoestadísticas. Diario Oficial de la Federación 14/01/2008. Primera sección. 2008.

[INALI], INSTITUTO NACIONAL DE LENGUAS INDÍGENAS. Catálogo de lenguas indígenas nacionales: Variantes lingüísticas de México con sus autodenominaciones $y$ referencias geoestadísticas.2019. Acceso el 16 ene 2019.

JIMÉNEZ -SIERRA, C. L.; SOSA- RAMIREZ, J.; CORTÉS- CALVA, P.; SOLÍS CÁMARA, A. B.; INIIGUEZ DÁVALOS, L. I.; ORTEGA- RUBIO, A. México país megadiverso y la relevancia de las 
áreas naturales protegidas. Investigación y ciencia, 60, 16-22.

LADIO, A. Los desafíos actuales de la Etnobotánica. Boletín Latinoamericano y del caribe de

Plantas Medicinales y Aromáticas, 5(2), 1-2. 2006.

LEVY- TACHER, S. I.; AGUIRRE- RIVERA, J. R.; GARCÍA- PÉREZ, J. D.; MARTÍNEZ

ROMERO, M. M. Aspectos florísticos de Lacanhá Chansayab, Selva Lacandona, Chiapas. Acta

Botánica Mexicana, (77), 69-97. 2006.

LEYVA SOLANO, X. Catequistas, misioneros y tradiciones en las cañadas. In J. P. VIQUEIRA; M.

H. RUZ (Eds.), Chiapas. Los rumbos de otra historia. México: Instituto de Investigaciones Filosóficas /CIESAS/UNAM. 2004. 508 p.

LIMÓN-AGUIRRE, F. Conocimiento cultural y existencia entre los chuj. El Colegio de la Frontera Sur/CDI. 2010.

LIMÓN-AGUIRRE, F. Agua y subjetividad entre los chuj. El respeto al corazón del agua. En: Murillo Licea D. Edit. Culturas del agua y cosmovisión india. En un contexto de diversidad cultural. Instituto Mexicano de tecnología del agua. 2012. Pp.59-81.

LINARES BRAVO, B. C. Género, territorio y reconversión productiva a palma de aceite en el Valle del Tulijá, Chiapas, México. [Tesis de Maestría]. Colegio de postgraduados, Montecillo, Texcoco, Edo. de México. 2014.

LOBATO, R. Qu'ixin Qu'inal. La colonización de la Selva Lacandona. México. D.F.: INAHSEP. 1979. 70-82 pp.

Maffi, L. Language, knowledge and environment. In L. MAFFI, L. (Ed.), On biocultural diversity: linking language, knowledge and the environment. Washington and London: Smithsonian institution press. $2001.578 \mathrm{p}$.

MAFFI, L. Linguistic, Cultural and Biological Diversity. Annual review of Antropology, 34(1), 599-617. 2005.

MAFFI, L. Biocultural diversity and sustainability. In. J. PRETTY; A. S. BALL; T. BENTON; G. JULIA; D. R. LEE; D. ORR; M. J. PREFFER; H. WARD (Eds.), The sage Handbook of Environment and society (pp 267-278). SAGE publication. 2007.

MADONADO-KOERDELL, M. La etnobotánica: tres puntos de vista y una perspectiva. (A.

Barrera, Ed.) (sexta). México: Insituto nacional de investigaciones sobre recursos bióticos. 1979.

MONDRAGÓN RÍOS, R. Chiapas. In L. Huicochea Gómez (Coord.), Herbolaria curativa y sanadora. Secretaría de Cultura del Gobierno del Estado de Campeche. San Francisco de Campeche, Campeche: Pámpano Servicios Editoriales S. A de C.V. 2014. 298 p.

MÜLLERRIED, F. K. G. Fisiografía de Chiapas. In F. K. G. Müllerried (Ed.), Geología de Chiapas. México D.F.: Editorial Cultura. 1957a. p 13-29.

MÜLLERRIED, F. K. G. Morfología de Chiapas. In F. K. G. Müllerried (Ed.), Geología de Chiapas, México D.F.: Editorial Cultura. 1957b. p. 59-68

NAVARRO-SMITH, A. El certificado agrario: símbolo de la victoria en la lucha por la tierra. Centro internacional de casos Tecnológico de Monterrety (25104). 2006.

NAVARRO-SMITH, A. “iQué esperanza que alguien dijera: yo soy priista!”. Desacatos, (26),93118.2008.

NEMOGÁ G.; DOMICÓ, J.; MOLINA, A. Designing biocultural protocols with the Embera people of Colombia. Langscape Magazine, 7(1),7. 2008.

NEMOGÁ, G, R. Diversidad biocultural: innovando en investigación para la conservación. Acta Biológica Colombiana, 1(21), 311-319. 2016.

OVIEDO, G.; NOEJOVICH, F.; ZAMUDIO, T. Desafíos para el mantenimiento de los conocimientos tradicionales en América Latina. Resumen Ejecutivo del Informe Integrado sobre la Situación y Tendencias Relativas a los Conocimientos, Innovaciones y Prácticas de las Comunidades Indígenas y Locales Pertinentes a las Conservación y Utilización sostenible de la Diversidad Biológica, 8, 1-10. 2007.

PAGE, J. Religión y política en el consumo de prácticas médicas en una comunidad tzotzil de

Simojovel de Allende. Universidad Autónoma de Chiapas. Tuxtla Gutiérrez, Chiapas, México. 1990.

PAGE PLIEGO, J. T. Yombil, Puesta su flor en el altar. Una mirada a la etnobotánica en

Oxchuc, Chiapas. México: Instituto de Investigaciones Antropológicas/ Universidad Nacional Autónoma de México. 2010.

PEREZ-FARRERA, M. A.; MARTÍNEZ- CAMILO, R..; MARTÍNEZ- MELÉNDEZ, N.; FARRERA- SARMIENTO, O.; VILLALOBOS-MÉNDEZ, S. M. (2004). Listado florístico del Cerro 
Quetzal (Polígono III) de la Reserva de la Biosfera El Triunfo, Chiapas, México. Botanical Science, 90(2),1-30. 2004.

PORTO- GONÇALVES, C. W. Amazonía encrucijada civilizatoria. Tensiones territoriales en curso. Carlos Walter Porto-Gonçalves. - La Paz: Instituto para el Desarrollo Rural de Sudamérica; CIDES- UMSA. 2018. 238 p.

PORTO- GONÇALVES, C. W. Latifundios genéticos y existencia indígena. http://www.biodiversidadla.org/Documentos/Latifundios-geneticos-y-existencia-indigena.2006.

Acceso: 25 agos 2018

R. RAMIREZ, C. Etnobotánica y la pérdida de conocimiento tradicional en el siglo 21. Etnobotany Research and Biocultural, 5, 241-244. 2007.

REYES, A. Red de etnoecología y patrimonio biocultural. Red de etnoecología y patrimonio biocultural. México. CONACyT. 2002.

SANABRIA-DIAGO, O. L. La visión cultural de la etnobotánica. Simposio etnobotánica con enfoque biocultural. Colombia: Simposio. 2013.

SARUKHÁN, J.; KOLEFF, P.; CARABIAS, J.; SOBERÓN, J.; DIRZO, R.; LLORENTEBUSQUETS, J.; HALFTER, G.; GONZÁLEZ, R.; MARCH, I.; MOHAR, A.; ANTA, S.; DE LA MAZA, J. Capital Natural de México. Síntesis: conocimiento actual y perspectivas de sustentabilidad. Comisión Nacional para el Uso y Conocimiento de la Biodiversidad. 104. p2009
SIC.
M.
Lenguas
indígenas
de
Chiapas.

https://sic.cultura.gob.mx/lista.php?table=inali_li\&tado_id=7\&municipio_id=-1. 2018.Acceso:10 feb 2019.

TOLEDO, V. M.; BATIS, A. I.; BECERRA, R.; MARTÍNEZ, E.; RAMOS, C. H. La selva útil: Etnobotánica cuantitativa de los grupos indígenas del trópico húmedo de México. Interciencia,20(40), 177-187. 1995.

TOLEDO, V. M.; BARRERA- BASSOLS, N. La Memoria biocultural. Barcelona: Icaria editorial, S. A. ISBN: 978-84-9888-001-4. Depósito legal: B-19.711-2008. 2008.

TOLEDO, V.M. Red de etnoecología y patrimonio biocultural. Red de Etnoecología y Patrimonio Biocultural. México. 2012.

UBIERGO- CORVALÁN, P.; RODRÍGUEZ GALVÁN, G.; ZARAGOZA MARTÍNEZ, L.; GUEVARA HERNÁNDEZ, F. Etnobtánica maya-ch'ol, al rescate del conocimiento tradicional en agroecosistemas de Chiapas. (México). Instituto de Estudios Indígenas/UNACH. Revista La Quinta Ola del Progreso de la Humanidad. ISSN: 2477-9229. 2016.

VERA CORTÉS, G.; MARTÍNEZ LÓPEZ C.O. Vulnerabilidad social a desastres en Tabasco. Conmemoración del desastre de 2007. Rev. Geo. Sur, 8(12),1-14.2014.

VILLAFUERTE SOLÍS, D.; GARCÍA AGUILAR, M. C. Tres ciclos migratorios en Chiapas: interno, regional e internacional. Migración y Desarrollo, 22(12).3-17. 2014.

VILLASEÑOR, J. L. La familia Asteraceae en México. Revista Sociedad Mexicana de Historia Natural Esp. (XLIV), 117-120. 1993.

VILLASEÑOR, J. L. Diversidad y Distribución de las magnoliophyta de México. Interciencia, 28(3), 160-167. 2003.

VIQUEIRA, J. P. Las causas de una rebelión india: Chiapas 1712. In J. P. VIQUEIRA; M. H. RUZ (Eds.), Chiapas. Los rumbos de otra historia. Instituto de investigaciones Filosóficas/ CIESAS/UNAM. 2004. 508 p.

VOGT, E. Z. Ofrendas para los dioses. (Primera Ed.). México D.F.: Harvard University Press. 1979. 